\title{
Congruence between student and instructor perceptions of clinical teaching in paediatricst
}

\author{
F. M. WOLF $¥ \&$ E. V. TURNER $\$$ \\ $\ddagger$ Department of Postgraduate Medicine and Health Professions Education, University of Michigan, Ann \\ Arbor, Michigan and $\$$ Department of Pediatrics, Ohio State University, Columbus, Ohio
}

Summary. The purpose of this study was to examine the similarities and differences in what students and instructors perceive to be the importance, and instructor use of, representative effective clinical teaching skills noted in the literature. Teaching staff members $(n=74)$ and students $(n=96)$ in three successive quarters in a required clerkship in paediatrics completed parallel forms of a clinical teaching survey. Providing feedback and positive reinforcement, showing personal interest in students, communicating knowledge and learning objectives effectively, motivating students, exhibiting knowledge of current practice and physical diagnosis, and spending time reviewing histories and demonstrating and supervising physical examinations were all thought to be important by both students and teaching staff members. Both students and instructors, however, perceived history/physical examination skills to be somewhat less important than the other clinical teaching skills, although instructors believed this skill to be significantly more important than did students. In general there was a great deal of consistency and reliability among student and instructor perceptions of the importance of these representative effective clinical teaching skills. In contrast, teaching staff members consistently believed they used each skill significantly more

tPortions of this paper were presented at the annual meeting of the American Educational Research Association, San Francisco, April 1986.

Correspondence: Dr F. M. Wolf, Department of Postgraduate Medicine and Health Professions Education, University of Michigan, G1208 Towsley Center, Ann Arbor, Michigan 48109-0201, USA. than students judged they did. Not surprisingly, the more important that teaching staff members believed each skill to be, the more they reported using that skill in their own teaching. These findings suggest that it is important for clinical instructors to be vigilant in assessing the effectiveness of their teaching methods.

Key words: pediatrics/ ${ }^{*}$ educ; ${ }^{*}$ clinical clerkship; *teaching; students, medical; clinical competence

\section{Introduction}

It is widely recognized that "clinical teaching . . . is the critical phase of medical training that potentially can have the most impact on students' application of medical knowledge to patient care' (Collins et al . 1978, p. 152). While there appears to be consistency in the studies of what constitutes effective and ineffective clinical teaching (Stritter et al. 1975; Irby 1977; Bazuin \& Yonke 1978; Collins et al. 1978; Hook \& Rosenshine 1979; Stritter \& Flair 1980; Cross 1981), few medical teachers receive formal teacher training, although teaching staff development programmes are increasing (e.g. Stritter \& Hain 1977; Bazuin \& Yonke 1978; Greenberg et al. 1984). Instead, most clinical instructors typically learn to teach through a process of trial and error (Jason 1978). Teaching staff members are receptive to such training programmes if they are well designed and meet their perceived needs (Knowles 1978). While there is general agreement concerning the skills comprising effective clinical teaching, little is known concerning the relationship between how important 
each skill is considered and how much teaching staff members use them in their own clinical instruction. It is likely that those teaching skills that instructors consider to be more important would be used more often by them. Additionally, congruence between instructor and student perceptions of highly important and frequently used skills would likely enhance learning. Lack of congruence, on the other hand, might indicate areas of potential conflict, inhibit learning, and suggest appropriate areas for teaching staff examination and development activities (Whitman \& Schwenk 1982; Steinmetz 1985). This thesis also is consistent with adult learning and instructional approaches which advocate increased student responsibility for learning and involvement in the focus and mode of presentation of content (Knowles 1978; Cross 1981).

In a study designed to discover the characteristics and differences among instructor and student perceptions of the relevant topics for evaluation by medical students, students generally rated each topic as significantly more appropriate to evaluate than did instructors, even though the correlation of mean teaching staff and student responses $(0.90)$ suggested that these two groups rank ordered the importance of these items in very similar ways' (Donnelly et al. 1979, p. 166). Another study (Gormisch et al. 1972) found that junior medical students and department chairmen differed in their ratings of individual teachers. Still another study indicated that senior medical students' views regarding medical school climate were consistent with the views of the clinical teaching staff, but that the basic science teaching staff were more self-critical when compared with first-year students (Sheehan 1970).

The objectives of this study were to examine the similarities and differences in what students and clinical instructors perceive to be the importance, and instructor use of, representative effective clinical teaching skills noted in the literature. This information was used in the preparation of a clinical teaching skills workshop for teaching staff members. The specific research questions addressed were: (1) do students and instructors, respectively, believe all skills to be equally important? (2) are there differences between student and instructor ratings of the importance of each skill? (3) do students and instructors, respectively, believe instructors use any of these skills more frequently than others? (4) are there differences between student and instructor perceptions of teachers' use of each skill? (5) do students and instructors, respectively, who rate a skill as more important in comparison to their peers, also believe the teaching staff use the skill more frequently? (6) are student perceptions associated with their amount of prior clinical experience?

\section{Methods}

Parallel forms of a clinical teaching survey were sent to all instructors in the Department of Pediatrics, Ohio State University and to all students in the required clinical clerkship in paediatrics over three successive quarters. The instructor survey served as a needs assessment for future clinical teaching instruction, and contained additional questions (not addressed in this study) concerning the desired content and format for such instruction. The student survey only contained the clinical skills questions from the teaching staff survey form, in addition to information about which other clinical clerkships they had completed. Six clinical teaching skill categories representative of those in the literature that are thought to be effective were rated each on a 5-point scale, from 'not important at all' to 'extremely important'. Teaching staff members were then asked to rate how often they believed they used each skill in their own clinical teaching, while students were asked to rate how often they believed the paediatrics teaching staff used them. Both instructor and student ratings of use were made on a 5-point scale, ranging from 'almost never', 'infrequently', 'sometimes', 'regularly', and 'almost always'.

Seventy-one of 103 members of the teaching staff $(68.9 \%)$ and 96 of 97 students returned the completed survey. Three interested house officers also completed the survey, increasing the size of the instructor group to 74 . Only those surveys that contained complete responses for the importance or use questions, respectively, for all six skills were included in the respective data analyses. 
A group (student/instructor) by , clinical teaching skills two-way analysis of variance with skills as a repeated measure was performed, once for 'importance' and again for 'use'. Simple effects followed by Tukey $A$ (Honestly Significant Differences) post-hoc tests (Winer 1971) were used to test for differences among the mean ratings for six skills for students and instructors, respectively. Mean differences between student and instructor ratings for each skill were tested by an analysis of the simple effects (using harmonic means because of unequal $n \mathrm{~s}$ ), as the comparisons between two group means do not require further post-hoc analyses. Pearson correlations were used to determine the relationships between the importance and use of each skill, and to estimate the relationship between student ratings and the number of prior clinical clerkships they had completed. Spearman rankorder correlations were not used because of the large number of tie scores, which made this procedure inappropriate.

\section{Results}

Importance of clinical teaching skills

Examination of the first research question of whether students and instructors each believed all six skills to be equally important was answered negatively. Analysis of variance results for ratings of the importance of six clinical teaching skills indicated no significant main effect $(F=0.32)$ between student and teaching staff ratings across all the skills. There was, however, a significant main effect for skills, $F(5,785)=32.57, P<0.001$, indicating differences in the importance given to the various skills. The interaction between type of skill and group also was significant, $F(5,785)=3 \cdot 76, P<$ 0.003 , suggesting differences between students and instructors in some, but not all, of the skills. Mean ratings of the importance of the skills provided by students and instructors are summarized in Table 1. All skills were considered to be relatively important by both groups, with mean ratings ranging between 3.62 and 4.64 on a $5 \cdot 0$ scale.

A significant simple effect for students indicated mean differences among the ratings of importance of the skills $(F=35.25, P<0.001)$. Students rated the two skill categories, (1) 'spend time reviewing histories, demonstrate and supervise physical examination and procedures and (2) 'show knowledge of physical diagnosis, current paediatrics, quote literature', as significantly less important $(P<0.05)$ than the other four, (3) 'provide feedback, positive reinforce-

Table 1. Summary of student $(n=94)$ and instructor $(n=65)$ mean (standard deviation) ratings of the importance of six clinical teaching skills

\begin{tabular}{lcccc}
\hline Clinical teaching skill & Student & Instructor & $F$ & $P$ \\
\hline (1) Provide feedback, positive reinforcement, correct & $4 \cdot 64^{\mathrm{b}}$ & $4 \cdot 45^{\mathrm{b}}$ & 2.95 & $\mathrm{NS}$ \\
without belittling & $(0.62)$ & $(0.69)$ & & \\
(2) Show personal interest in students, listen attentively, & $4.49^{\mathrm{b}, \mathrm{d}}$ & $4.42^{\mathrm{b}}$ & 0.40 & $\mathrm{NS}$ \\
encourage active participation & $(0.71)$ & $(0.77)$ & & \\
(3) Communicate knowledge, what is expected to be & $4 \cdot 43^{\mathrm{c}, \mathrm{d}}$ & $4.37^{\mathrm{b}}$ & 0.29 & $\mathrm{NS}$ \\
learned, explain clearly, emphasize the important & $(0.75)$ & $(0.72)$ & & \\
(4) Dynamic, energetic, enjoy teaching, motivate students & $4.33^{\mathrm{c}, \mathrm{d}}$ & $4 \cdot 38^{\mathrm{b}}$ & 0.20 & $\mathrm{NS}$ \\
& $(0.72)$ & $(0.78)$ & & \\
(5) Show knowledge of physical diagnosis, current & $3.79^{\mathrm{a}}$ & $3.89^{\mathrm{a}}$ & 0.82 & $\mathrm{NS}$ \\
paediatrics, quote literature & $(0.88)$ & $(0.90)$ & & \\
(6) Spend time reviewing histories, demonstrate & $3.62^{\mathrm{a}}$ & $4.05^{\mathrm{a}}$ & 15.02 & $<0.001$ \\
and supervise physical examinations and procedures & $(1.01)$ & $(0.89)$ & & \\
\hline
\end{tabular}

Note. Scores range from 1 to 5 , with higher numbers indicating greater importance.

Identical superscript letters within a column indicate no significant difference between those skills. For example, ${ }^{2}$ in the student column indicates that mean student ratings for skills 5 and 6 are not significantly different, but that they differ significantly from each of the mean ratings for the other four skills. The $F$ and $P$ values in the two right-hand columns indicate the significance of the difference between student and instructor ratings for each skill. 


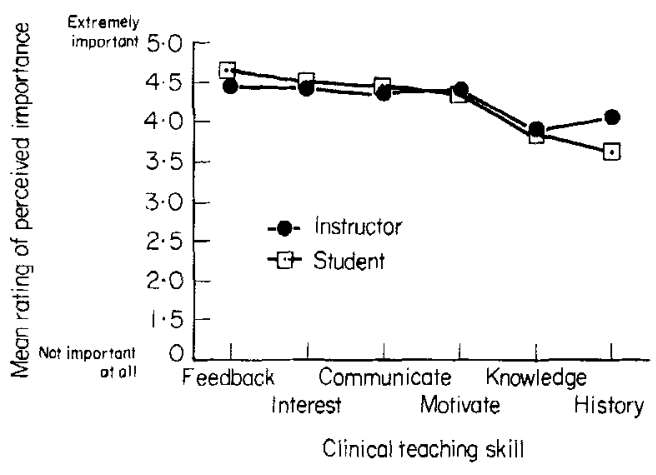

Figure 1. Mean ratings of the importance of six clinical teaching skills by students and instructors in paediatrics.

ment, correct without belittling', (4) 'show personal interest in students, listen attentively, encourage active participation', (5) 'communicate knowledge, what is expected to be learned, explain clearly, emphasize the important', and (6) 'dynamic, energetic, enjoy teaching, motivate the students'. In addition, providing feedback was considered significantly more important $(P<0.05)$ than either motivation or good communication skills. These effects may be more clearly seen by looking at the student mean ratings in Fig. 1.

A significant $(F=7.45, P<0.001)$ simple effect for instructor ratings of importance also can be understood by referring to Fig. 1. Instructors believed knowledge and history teaching skills to be significantly $(P<0 \cdot 01)$ less important than the other four skills. No other mean differences were significant.

Results pertaining to the second research question of whether there are differences between student and teaching staff perceptions of the importance of each skill indicated great consistency between the two groups. Differences between student and instructor ratings of the importance of each skill summarized in Table 1 and Fig. 1 indicated that only the difference for history and physical examination skills was significant $(P<0 \cdot 001)$, with instructors believing these to be more important than did students. The correlation of mean instructor and student responses was 0.95 , indicating that these two groups rank ordered the importance of these six skills very similarly, even given this different perception of history/physical examination skills.

Use of dinical teaching skills

The third research question addressed whether students and instructors each believed that instructors make more frequent use of some skills than others, which they both did. Analysis of variance results for ratings of instructor use of these skills indicated significant $(P<0.001)$ main effects for differences (1) between students and instructors, $F(1,134)=32 \cdot 84,(2)$ among the six skills, $F(5,670)=23.97$, and (3) for the interaction between groups and skills, $F(5,670)=$ $4 \cdot 48$.

These results indicated that students, as well as instructors, perceived instructor use of these skills to vary significantly $(P<0.001$ in both instances) depending upon the skill. Post-hoc Tukey tests indicated that students perceived instructors to devote less time $(P<0.01)$ to reviewing histories and physical examinations than to any of the others. Students also believed instructors used communication skills significantly less $(P<0.05)$ than either knowledge- or interest-related skills. Differences in ratings of use by instructors were somewhat more complex. History/physical examination skills were rated as being used significantly less than all the other skills except knowledge skills. Knowledge skills were in turn rated significantly less used than the others, except for motivation. Motivation, in turn, was rated less than both feedback and interest, while communication was rated less used than interest in students.

Examination of the fourth research question of differences between student and instructor perceptions of instructor use of each skill indicated that instructors believed they used each skill more frequently than did students, as can be seen in Table 2 and Fig. 2. As these results suggest, there were many more differences between student and instructor ratings of instructor use of these clinical teaching skills than for the ratings of their importance. However, the correlation of mean instructor and student responses for use was 0.70 , again suggesting similarity of the rank order of the use of these skills by the two groups even though there were many mean differences. 


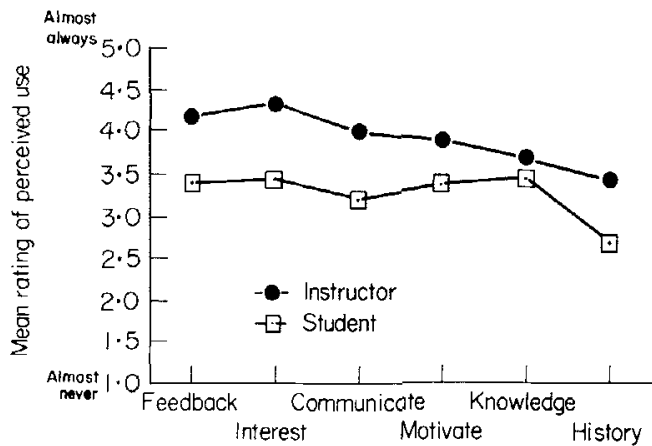

Figure 2. Mean ratings of instructor use of six clinical teaching skills by students and instructors in paediatrics.

\section{Correlates of importance and use}

The fifth research question examined the relationship between ratings of importance and use for each skill separately for the student and instructor groups. Instructor ratings indicated a consistent positive and significant $(P<0.01)$ relationship for each skill, with correlations ranging from 0.35 to 0.55 . That is, the more instructors believed they used a skill, the more important they believed that skill to be, or conversely, the more important instructors rated a given skill, the more likely they were to use that skill in their own teaching. The relationship between the importance given to each skill by students and their perceptions of the degree to which they were used by instructors was less salient. Correlations for only two of the six skills were significant: history/physical examination skills $(r=0.31, P<0.01)$ and knowledge skills $(r$ $=0.27, P<0.05$ ).

The final question examining the relationship between the amount of students' prior clinical experience and their ratings indicated no relationship for ratings of importance $(r=-0 \cdot 15$ to $+0 \cdot 14)$. There was, however, a consistent inverse relationship between the number of clinical rotations experienced and ratings of teaching staff use. This suggests that students having had more rotations tended to perceive less instructor use of these skills. This statement must be qualified as these correlations were significant for only three of the six skills: knowledge $(r=-0 \cdot 36$, $P<0.01)$, history $(r=-0.35, P<0.01)$, and feedback $(r=-0.27, P<0.05)$, with others not large enough to reach statistical significance;

Table 2. Summary of student $(n=79)$ and instructor $(n=57)$ mean (standard deviation) ratings of teaching staff use of six clinical teaching skills

\begin{tabular}{|c|c|c|c|c|c|}
\hline & Clinical teaching skill & Student & Instructor & $F$ & $P$ \\
\hline (1) & $\begin{array}{l}\text { Provide feedback, positive reinforcement, correct } \\
\text { without belittling }\end{array}$ & $\begin{array}{l}3 \cdot 39^{\mathrm{b}, c, d} \\
(0 \cdot 87)\end{array}$ & $\begin{array}{c}4 \cdot 16^{d} \\
(0 \cdot 73)\end{array}$ & 43.62 & $0 \cdot 001$ \\
\hline (2) & $\begin{array}{l}\text { Show personal interest in students, listen attentively, } \\
\text { encourage active participation }\end{array}$ & $\begin{array}{l}3.42^{d} \\
(0.87)\end{array}$ & $\begin{array}{c}4 \cdot 30 \\
(0.73)\end{array}$ & 56.98 & 0.001 \\
\hline (3) & $\begin{array}{l}\text { Communicate knowledge, what is expected to be } \\
\text { learned, explain clearly, emphasize the important }\end{array}$ & $\begin{array}{r}3 \cdot 19^{\mathrm{b}} \\
(0 \cdot 85)\end{array}$ & $\begin{array}{l}3.98^{c, d} \\
(0 \cdot 64)\end{array}$ & 45.92 & $0 \cdot 001$ \\
\hline (4) & Dynamic, energetic, enjoy teaching, motivate students & $\begin{array}{l}3 \cdot 38^{\mathrm{b}, \mathrm{c}, \mathrm{d}} \\
(0 \cdot 99)\end{array}$ & $\begin{array}{l}3.88^{\mathrm{b}, \mathrm{c}} \\
(0.87)\end{array}$ & $18 \cdot 39$ & 0.001 \\
\hline (5) & $\begin{array}{l}\text { Show knowledge of physical diagnosis, current } \\
\text { paediatrics, quote literature }\end{array}$ & $\begin{array}{r}3 \cdot 44^{\mathrm{d}} \\
(0 \cdot 96)\end{array}$ & $\begin{array}{l}3 \cdot 67^{a, b} \\
(0 \cdot 76)\end{array}$ & $3 \cdot 89$ & $0-05$ \\
\hline (6) & $\begin{array}{l}\text { Spend time reviewing histories, demonstrate } \\
\text { and supervise physical examinations and procedures }\end{array}$ & $\begin{array}{r}2 \cdot 67^{2} \\
(1 \cdot 10)\end{array}$ & $\begin{array}{r}3 \cdot 42^{a} \\
(1 \cdot 10)\end{array}$ & $41 \cdot 39$ & $0 \cdot 001$ \\
\hline
\end{tabular}

Note. Scores range from 1 to 5 , with higher numbers indicating greater use.

Identical superscript letters within a column indicate no significant difference between those skills. For example, ${ }^{2}$ in the student column indicates that mean student rating for skill 6 differs significantly from the mean ratings for each of the other five skills; ${ }^{b}$ indicates that mean ratings for skills 1,3 and 4 do not differ from each other, but are significantly different from the other three skills, etc. No letter indicates that skill differs significantly from other items. The $F$ and $P$ values in the two right-hand columns indicate the significance of the difference between student and faculty ratings for each skill. 
motivation $(r=-0 \cdot 21, P<0 \cdot 06)$, communication $(r=-0 \cdot 16, \mathrm{NS})$, and interest $(r=-0 \cdot 13$, NS).

\section{Discussion}

The findings of this study are best interpreted by keeping in mind that the research questions pertaining to instructor use of selected clinical teaching skills were examined by obtaining student and instructor perceptions of use and not actual observations of teaching. Additionally, student ratings were for instructors in general and not for specific individual teaching staff members. Furthermore, it is apparent that four of the skills, those relating to feedback, interest, communication and motivation, are more process-oriented teaching attributes, while skills related to knowledge and histories/physical examinations are more content-related skills in which the four process skills can be applied. This may help explain why the process skills in general were given more importance and perceived to be more widely used.

The similarity in rankings of importance and use, and of the magnitude of importance of these six skills, support the reliability of these clinical teaching skill categories. These findings suggest great consistency among students and instructors in their ratings of both the rank order and magnitude of the importance of these clinical teaching skills. This seems to parallel the previous finding (Donnelly et al. 1977) of high correspondence between the student and instructor rank order of importance of student evaluation topics, even given significantly different average ratings between the two groups. Less, although still somewhat high, consistency between the two groups in the rank ordering of instructors' use of these skills was also indicated. The one inconsistency in rank ordering was the teaching staff's belicf that they used communication skills more frequently than knowledge skills, while students believed just the opposite. Thus the pattern of use appeared to be perceived by students and teaching staff as somewhat similar even though there were discrepancies in their perceptions of the magnitude of use for each skill.

This lack of congruence between student and instructor average ratings of instructor use of these skills could provide guidelines for teaching staff development efforts. The finding that instructors believed they used each skill more frequently in their clinical teaching than students believed they did is consistent with the literature on classroom teaching, which indicates that teachers as a group have a tendency to rate themselves higher than do their students (Centra 1973; Kulik \& McKeachie 1975; Hook \& Rosenshine 1979). Being made aware of this discrepancy may motivate teaching staff to examine and perhaps change their own teaching behaviour, as suggested by the discrepancy evaluation model (Steinmetz 1985).

Students and teaching staff agreed that history and knowledge skills, although important, were both less important and used less than most of the other skills. It is quite possible that use of the other four process-oriented skills determines to some degree the learning value of the contentrelated teaching skills of reviewing histories and sharing knowledge as they are applied in particular instances. It is also possible that the process skills may be perceived as more important because by definition they can be applied to a wider range of situations than the two specific content skills. Students seem to stress this importance more than instructors, however, by giving greater emphasis to the role of feedback, positive reinforcement, and correcting without belittling. This is perhaps a reflection of their desire for personal supervision and guidance, but at the same time to be treated with respect as professionals, however fledgling, and not to be embarrassed by their instructors.

The positive association for members of teaching staff between importance and use for each skill suggests that these may be reinforcing each other. Interventions designed to increase one may impact favourably on the other. Finally, increased student clinical experience does not affect the importance students place on each of these skills, which was generally very high (average rating of $4 \cdot 21$ of a possible high rating of 5). Increased clinical exposure, however, tends to be associated with lower perceptions of actual teaching staff use of some of these skills. Whether this is a result of more accurate perceptions as a result of increased experience, or increasing criticalness as the excitement of a newer experience wears off, or whether other 
clerkships were perceived more favourably than paediatrics, remain competing hypotheses for further exploration.

In the aggregate, these findings do suggest a certain logical sequence in which the importance of all these clinical teaching skills is to some degree self-evident, which undoubtedly leads to their commensurate use by instructors, which in turn, is reflected somewhat in students' views. Thus a certain degree of similarity between the views of students and instructors should be anticipated. This expectation, however, may enhance the meaning of the differences between them and thereby the vigilance with which clinical instructors ought to view and assess the effectiveness of their own teaching methods.

\section{Acknowledgement}

We thank the anonymous referees for their helpful comments.

\section{References}

Bazuin C.H. \& Yonke A.M. (1978) Improvement of teaching skills in a clinical setting. Journal of Medical Education 53, 377-82.

Cantrell T. (1973) How do medical school staff learn to teach? Lancet ii, 724-7.

Centra J.A. (1973) Self ratings of college teachers: a comparison with student ratings. Journal of Educational Measurement 10, 287-95.

Collins G.F., Cassie J.M. \& Daggett C.J. (1978) The role of the attending physician in clinical training. Journal of Medical Education 53, 429-31.

Cross K.P. (1981) Adults as Leamers. Jossey-Bass, San Francisco.

Daggett C.J., Cassie J.M. \& Collins G.F. (1979) Research on clinical teaching. Review of Educational Research 49, 151-69.

Donnelly M. B., Puhl C., Fleisher D.S., Garrison J.H. \& Kaplan S. (1979) What should students evaluate? A comparison of faculty and student perceptions. Proceedings of the 18th Annual Conference on Research in Medical Education 18, 165-70.

Falvo D. \& Wright W.R. (1981) Assessment of residents' attitudes toward patient education. Journal of Medical Education 56, 200-1.

Gormisch D.S., Banford J.C., Rous S.N., Sall S. \& Rubin S. (1972) A comparison of student and department chairmen evaluation of teaching performances. Journal of Medical Education 47, 281-4.

Greenberg L.W., Goldberg R.M. \& Jewett L.S. (1984) Teaching in the clinical setting: factors influencing residents' perceptions, confidence and behaviour. Medical Education 18, 360-5.

Hook C.M. \& Rosenshine B.V. (1979) Accuracy of teacher reports of their classroom behavior. Review of Educational Research 49, 1-12.

Irby D.M. (1977) Clinical teacher effectiveness in medicine. Proceedings of the 16th Annual Conference on Research in Medical Education 16, 161-6.

Irby D. \& Rakestraw P. (1981) Evaluating clinical teaching in medicine. Journal of Medical Education $56,181-6$.

Jason H. (1978) Is faculty development necessary? In fact, what is it? Joumal of Medical Education 53, 442.

Knowles M. (1978) The Adult Learmer: A Neglected Species. 2nd edition. Gulf Publishing, Houston.

Kulik J.A. \& McKeachie W.J. (1975) The evaluation of teachers in higher education. In: Review of Research in Education, Vol. 3 (ed. by F.N. Kerlinger), pp. 210-40. Peacock, Itaska, Illinois.

Page G.G., Foley R.P. \& Pochyly D.F. (1975) A survey of interests in teacher training of health science faculty. British Journal of Medical Education 9, 182-7.

Rippy R.M. (1981) The Evaluation of Teaching in Medical Schools. Springer, New York.

Sheehan T.J. (1970) Medical school climate: comparative faculty and student views. Journal of Medical Education 45, 880-7.

Steinmetz A. (1985) The discrepancy evaluation model. In: Evaluation Models: Viewpoints on Educational and Human Services Evaluation (ed. by. G. Madaus, M.S. Scriven \& D.L. Stufflebeam), pp. 79-99. Kluwer-Nijhoff Publishing, Lancaster.

Stritter F.T., Baker R.M. \& McCaghie W.C. (1983) Congruence between residents' and clinical instructors' perceptions of teaching in outpatient care centers. Medical Education 17, 385-9.

Stritter F.T. \& Flair M.D. (1980) Effective Clinical Teaching. NIH/National Library of Medicine, Bethesda, Maryland.

Stritter F. T. \& Hain J. D. (1977) A workshop in clinical teaching. Journal of Medical Education 52, 155-7.

Stritter F.T., Hain J.D. \& Grimes D. A. (1975) Clinical teaching reexamined. Journal of Medical Education 50, 876-82.

Whitman N. \& Schwenk T. (1982) Faculty evaluation as a means of faculty development. Journal of Family Practice 14, 1097-101.

Winer B.J. (1971) Statistical Principles in Experimental Design. 2nd edition. McGraw-Hill, New York.

Received 4 May 1988; editorial comments to authors 17 June 1988; accepted for publication 15 August 1988 